\title{
Los santos peruanos dominicos como personajes literarios en las tradiciones de Ricardo Palma'
}

\author{
Iván Rodríguez Chávez \\ Universidad Ricardo Palma \\ rector@urp.edu.pe
}

\section{Resumen}

En este estudio se explica la incorporación de los dos santos peruanos dominicos: Santa Rosa de Lima y San Martín de Porres como personajes literarios en las Tradiciones de Ricardo Palma, en las que este autor los presenta en su dimensión humana, ligados a menesteres cotidianos sencillos y humildes. Esta tradición es una narración breve, con lenguaje coloquial y un fondo de humor esparcido en todo el texto y concentrado en alguna parte de este. Los acoge, por su raigambre popular, la simpatía que despiertan en el lector, en aspectos de la vida que se prestan para constituir una literatura laica.

Palabras clave: santidad, humildad, sociedad, familia, caridad, obediencia.

\section{Abstract}

This study explains the addition of two Peruvian Dominican Saints: Saint Rose of Lima and Saint Martin de Porres as literary characters in the Traditions of Ricardo Palma. The author portrays them in their human dimension, tied to their ordinary and humble daily chores. The tradition is a brief narrative, written in a colloquial form of the language, with a humorous background scattered throughout the text, yet focused on some sections of it. They were chosen because of their roots to the people, how appealing they are to the reader, in aspects of their lives defined as secular literature.

Keywords: holiness, humility, society, family, charity, obedience.

1 Ponencia presentada en el IV Coloquio Internacional de Traducción Monacal (Proyecto I+D Ref.: FFI20 14-59140-P Catalogación y estudio de las traducciones de los dominicos españoles e iberoamericanos), organizado por la Universidad de Valladolid y Università di Bologna, del 04-09-2017 al 05-09-2017. 
Iván Rodríguez Chávez, Doctor y magister en Educación, profesor decastellanoy literaturay abogado por la Universidad Nacional Mayor de San Marcos. Docente universitario en literatura peruana, introducción al Derecho y legislación universitaria. Ex Presidente de la Asamblea Nacional de Rectores. Ex Presidente del Consejo Universitario Andino (CONSUAN) y del Consejo Universitario Iberoamericano (CUIB). Ex miembro del Consejo Nacional de Educación, Presidente de la Asociación de Universidades del Perú. Rector de la Universidad Ricardo Palma. Recibió la más alta condecoración "Palmas Magisteriales en el grado de Amauta" otorgado por el Ministerio de Educación del Perú. Participa en congresos y certámenes literarios y universitarios. Autor de libros, artículos y ponencias sobre literatura peruana, educación y legislación universitaria, que se publican en revistas universitarias y prensa escrita. 


\section{Introducción}

Es intención de este artículo vincular la religión con la literatura. Para ello, se ha escogido a dos santos peruanos dominicos: Santa Rosa de Lima y San Martín de Porres en una perspectiva humana captada por el escritor. Se trata de algunos aspectos de sus vidas aptos para construir un mensaje estético de admiración que, a la vez, representen la imagen que sus conductas proyectan sobre el resto de la población. Esta incorporación en la literatura les otorga una configuración de personajes literarios con muchas cualidades compatibles con el arte que exigen del escritor un tratamiento fino, cuidadoso, que no desfigure a su protagonista.

Ricardo Palma (Lima, 1833-1919) es uno de los narradores que en sus tradiciones ha logrado fabular historias con ideas y lenguaje sencillos, de fácil y breve discurso, pero efectivas al resaltar las cualidades sobrenaturales de los santos, haciéndolos sentir cercanos a la experiencia de los lectores, con una presentación discursiva en la que la santidad se pone el ropaje de lo terreno que le viene como pura humanidad.

Tal vez su filiación romántica haya contribuido a este producto en tanto que privilegia lo sentimental sobre lo racional, valora lo local sobre lo universal y dulcifica las acciones y los perfiles con la primacía de las formas del amor como sentimiento deseado y necesitado por todos. Le agrega el poder imaginativo de animación y su no disimulado sentido del humor.

\section{El marco histórico}

La más antigua relación de los dominicos con el Perú se retrotrae a la Capitulación de Toledo de 1529, en la que se concertó que Pizarro estaba obligado a "llevar consigo varios religiosos que instruyeren en la fe cristiana a los nativos de Nueva Castilla" (Hampe Martínez, 1998:198, t. II) y, siguiendo a este mismo 
historiador, “... se determinó nombrar al efecto a seis frailes dominicos..." (Ibídem), entre los cuales figuraba fray Vicente de Valverde que "vino a ser el único clérigo regular que permaneció en la hueste y es natural, por lo tanto, que le tocase formular el requerimiento a Atahualpa en la plaza de Cajamarca" (Ibídem). Vale decir, que Valverde aparece en el escenario peruano al lado de Pizarro, acompañándolo en su marcha al Cusco. El monarca, en mérito a sus servicios lo propone a Roma como el primer obispo del Cusco, declarándolo, además, protector de los indios. A los tres años del ejercicio de su gobierno, Valverde murió en 1541, en la isla de Puná, víctima de un ataque de los naturales.

Armando Nieto Vélez, a la Capitulación de Toledo agrega como fuente documental de la presencia en el Perú de los dominicos, "la carta de la reina Juana al Provincial de Santo Domingo (21 de abril de 1529)" (1981:429, t. XI). A la vez, ordena a Hernando de Luque "favorezca a los seis dominicos de la expedición pizarrista" y "al propio conquistador que les dé terreno y casas" (Ibídem).

Posteriormente irán a la gobernación de Nueva Castilla otro grupo de dominicos entre los cuales estarán "los padres Francisco Martínez Toscano y Agustín de Zúñiga, quienes obtuvieron de Roma la erección de la Provincia de San Juan Bautista (4 de enero de 1540)" (Ob.cit.:434, t. XI). Se designa bajo un régimen especial Prior Provincial a fray Tomás de San Martín y se "dispuso que el convento limeño estuviese bajo la advocación de Santa María del Rosario" (Ibídem). En el grupo de frailes fundadores figura Pedro Mártir, en condición de lego, de acuerdo a la relación consignada por Nieto Vélez.

Siendo años de organización de estas nuevas posesiones, en 1541 se creó el obispado de Lima, designándose como primer obispo al también dominico fray Jerónimo de Loayza, quien hizo ingreso a la Ciudad de los Reyes en julio de 1543 como efecto 
del traslado del obispado de Cartagena de Indias. Pocos años después se eleva al rango de arzobispado, independizándolo de Sevilla.

Jerónimo de Loayza celebra concilios, instituye la cátedra de quechua para los evangelizadores; imprime textos en lengua nativa para la cristianización de los naturales y atiende a los enfermos creando el primer hospital de indios.

Desempeñó el arzobispado hasta su muerte ocurrida en 1575.

Ante la vacancia de la prelatura, fue ungido arzobispo de Lima Toribio de Mogrovejo, quien tomó posesión de su cargo en 1581.

Nieto Vélez caracteriza a Toribio de Mogrovejo como "un pastor itinerante", que por esta razón "Le echaron el defecto de estar largas temporadas ausente de su sede"; y, que de los "veinticinco años de obispo solo ocho residió en Lima. El resto lo pasó visitando su territorio" (ob. cit.: 467, t. XI).

Creó el Seminario conciliar que lleva su nombre y organizó y realizó el III Concilio Limense, para el cual publicó el catecismo en castellano, quechua y aymara.

Enfrentó muchas dificultades con el poder virreinal.

En una de sus expediciones, Toribio de Mogrovejo confirmó a la futura Santa Rosa, cuando ella vivía en Quives.

Se dice que Mogrovejo aprendió quechua.

Fallece en Saña en marzo de 1606, cuando ejecutaba una visita apostólica por el norte.

Finalmente, en 1679 fue beatificado y canonizado en 1726 (Tauro del Pino, 2001:1693, t. 11). Nieto Vélez, el historiador 
jesuita de la Iglesia Católica en el Perú (1981), convocando su capacidad de síntesis intenta dar el perfil de la personalidad apostólica que define a Toribio de Mogrovejo, diciendo:

No se cansaba de instruir a quienes hacían objeto de su solicitud. Los buscaba aún en inverosímiles rincones de la geografía peruana. Los consolaba. Administraba los sacramentos, sin importarle la inclemencia del tiempo, las incomodidades, el hambre, la sed o el cansancio inherentes a peregrinaciones tan largas y fatigosas. Para él sólo contaban las palabras de San Pablo: Me gastaré y me desgastaré a mí mismo por vosotros (1981:469-70, t. XI).

\section{Caracterización social de la época}

Lima fue fundada por Francisco Pizarro el 18 de enero de 1535 con el nombre de Ciudad de los Reyes, para la sede del poder; por lo tanto, la ciudad más importante en la que vivirán españoles y criollos.

Además de los fines políticos y económicos de la fundación de ciudades, "los peninsulares necesitaron vivir agrupados en ciudades a fin de conservar su identidad cultural" (Hampe 1998:260, t. II).

$\mathrm{Al}$ año 1555 la composición de la población hispana ha sido calculada, ateniéndonos a la información proporcionada por Hampe, en 8,000 españoles, 350 clérigos y 1000 mujeres. "Debido al corto número de representantes del bello sexo que vinieron de la península, hubo solo una minoría de colonizadores que establecieron genuinos cuerpos familiares". Y, en razón "a la existencia de familias blancas en las ciudades, lograron implantarse costumbres y modos de pensamiento típicos de la sociedad ibérica" (Ob. cit.:261, t. II). 
En estas ciudades españolas en el Perú del siglo XVI, "Casi todos los estratos de la sociedad hispánica contaron con esclavos...", haciendo este hecho suponer que la población negra "llegó a superar en cantidad a los blancos". Estas, por vivir fuera de sus propios contextos culturales, "asimilaron con rapidez la cultura ibérica” (Ob. cit.:268, t. II).

Con los naturales, el fenómeno fue distinto. Por las disposiciones legales, los españoles estaban obligados a vivir separados de los llamados indios. Inicialmente, estos continuaban en sus poblaciones originarias hasta que se les obligó a asentarse en las reducciones. Pero sí había un pequeño grupo que fue incorporado al servicio doméstico. Fueron, entonces, ellos que se aculturaron "adoptando pautas hispánicas" (Ob. cit.:265, t. II).

También hubo, en la opinión de Hampe, otro tipo de ciudades como las de los asentamientos mineros y las portuarias, además de las reducciones, que en atención a fines tributarios y de control político concentraba a los naturales.

\section{Mentalidad y actitud religiosa dominante}

Francisco Diez de Velasco en su Breve Historia de las Religiones (2014) explica la expansión del cristianismo en tres grandes momentos históricos. Corresponde al segundo cuando por el descubrimiento, conquista y colonización del Nuevo Mundo, hace de la religión "un elemento de cristianización progresiva de las poblaciones americanas...” (2014:187).

Los antecedentes se remontan a la Bula del 4 de mayo de 1493 expedida por el Papa Alejandro VI, por la cual se "encarga oficialmente a la monarquía hispánica la conversión del Nuevo Mundo" (Nieto Vélez, 1981:420, t. XI). 
Ya fundada la Ciudad de los Reyes, José M. Valega, el catedrático sanmarquino estudioso del virreinato, plantea

Distinguir dos períodos en la evolución de la vida limeña: el que finaliza en el siglo XVII y el que comienza con la centuria siguiente. En el primero - que es el que nos interesa- de austeridad canónica, de hondo fervor religioso, distingue a Lima por su fuerte y sincera devoción. La aldea capitalina... vive para el culto. Lima no pierde instante para agradecer a la divinidad la gracia de la vida, del sueño, del aire, del sol, de la merienda y de la cena” (1939:308-309).

Situados siempre en el siglo XVI, Hampe Martínez, refiriendo el panorama de la conformación de las ciudades, observa que en "la segunda mitad de nuestra centuria, destacan en la fisonomía urbana los establecimientos de frailes y monjas, que brindaron a las ciudades el aspecto de inmensos monasterios" (Ob. cit.:262, t. II). Renglones adelante, en este mismo estudio, puntualiza que “... hubo numerosas doncellas y viudas que abrazaron la profesión eclesiástica, fuera porque sentían una auténtica vocación o bien porque consideraban de estirpe inferior a los sujetos en aptitud de casarse con ellas". (Ibídem).

Entre la segunda mitad del siglo XVI y la primera mitad del siglo XVII, Lima fue la ciudad del Nuevo Mundo que sirvió de escenario vital a cinco santos: dos peruanos que nacieron y murieron en Lima y tres españoles: Juan Masías, que llegó a Lima en 1620. Aquí abrazó la profesión religiosa como lego dominico. Falleció en Lima en 1645. Se conoció e hizo amistad con fray Martín de Porres.

Francisco Solano llegó a Lima en 1602 desempeñándose como guardián del convento de los descalzos del Rímac, falleciendo en 1610 . 
Toribio de Mogrovejo, el segundo arzobispo de Lima, asumió sus funciones en 1581 hasta 1606, año en que fallece en el pueblo de Saña cuando se encontraba llevando a cabo su última visita apostólica por los territorios y poblaciones de su muy extensa diócesis.

Resulta pertinente citar, una vez más, al R.P. Armando Nieto Vélez quien, a propósito del estudio del culto mariano y devociones populares, dice:

Quien juzgue con imparcialidad al paisaje religioso del Perú a partir del siglo XVI hasta nuestros días, comprobará cómo determinadas formas religiosas — de creencia y cultoimpregnan y coloran la vida individual y social del hombre de este país. No es solo un cambio de ambiente exterior, en el que huacas y adoratorios son sustituidos por ermitas, capillas y templos. Se trata también, y principalmente, de un cambio profundo en la psicología. (1981:521, t. XI).

Mención especial merece el caso de la hasta hoy beata Ana de los Ángeles Monteagudo, que nació en 1602 y vivió hasta su muerte (1686) en Arequipa. Ella fue "monja dominica contemplativa" (Martínez Puche, 2016:95). Consagrada a la profesión religiosa, pasó “su larga vida integrada a la comunidad del monasterio de Santa Catalina de Siena de monjas dominicas; primero como educanda, después como monja, dejándonos un mensaje de vida orante y misionera a la vez" (Ibídem). Inició su noviciado en 1618. Al año siguiente se consagra como religiosa de clausura. Durante su prolongada existencia ejercerá funciones de sacristana, maestra de novicias y priora. Su aureola de mística se proyectó más allá de los muros del convento. Sor María Elvira Catalá, autora de la síntesis biográfica, señala que atendía a los necesitados e impartía su bendición a los viajeros que la visitaban pidiéndole su oración (Ob.cit.:99). Sor Catalá agrega que "Los últimos diez años de su vida los pasó ciega y paralítica” (Ibídem). 
Ricardo Palma ha escrito una tradición convirtiéndola en personaje literario en una historia que la presenta profetizando hechos y situaciones que ocurrirían en la realidad. La tradición se titula El obispo del libro y la madre Monteagudo, que relata en primer plano los accidentes y vicisitudes del obispo Almoguera, asignándole a sor Ana un plano secundario, circunscrito a su participación como profetiza. Analizado el texto, la intención es más bien resaltar a sor Ana ubicando al obispo Almoguera como la historia que sirve de punto de apoyo para destacar los dones proféticos de ella. Ya en el segundo párrafo, la hace ingresar en escena diciendo:

En el monasterio de Santa Catalina de Arequipa había, allá por el siglo XVII, una monja conocida por la madre Ana de los Ángeles Monteagudo, de la cual refieren sus paisanos maravillas tales que la hacen acreedora a que Roma la canonice y coloque en los altares.

(Palma, 1953:435)

En el desarrollo del texto Palma tiene la oportunidad de insistir en las cualidades excepcionales de sor Ana al aludir a su "reputación de santidad" y "frecuentes... milagros y pronósticos...". A la vez, lamenta la pérdida del expediente de beatificación camino a Roma y finaliza el texto sintiendo el júbilo que, al retomarse estos trámites, los arequipeños "Pronto tendrán santa en casa”. (Palma, 1953:437)

\section{Los santos en la literatura}

Está ya aceptado que en los inicios de la occidentalización, siglos XVI y XVII, en el virreinato del Perú florecieron santos, beatos, sacerdotes y monjas muy virtuosos. No solo hubo una propagación en número de órdenes, congregaciones, conventos, capillas e iglesias, sino que el espíritu religioso 
estuvo infiltrado en toda la vida social e individual de las gentes de esos tiempos.

La lista cuantitativa y cualitativa es grande; pero de esta hemos escogido a dos peruanos y dominicos como son Santa Rosa de Lima y San Martín de Porres.

\subsection{Santa Rosa de Lima}

\subsubsection{Rasgos biográficos}

Nació en Lima el 30 de abril de 1586 y fue bautizada en la parroquia de San Sebastián en el Cercado de Lima con el nombre de Isabel Flores Oliva. Recibió la confirmación del arzobispo santo Toribio de Mogrovejo, en Quives, cuando su padre administraba una mina y había trasladado a dicha población a su familia. Salvador Velasco, en la biografía que inserta Martínez Puche en El año Dominicano (2016), informa que santo Toribio al confirmarla "le cambió el nombre de Isabel en Rosa” (2016:853).

La condición socioeconómica de la familia era limitada. El matrimonio entre Gaspar Flores y María Oliva llegó a tener trece hijos.

Se cuenta que la propia madre al verla a la bebé tan hermosa se prometió llamarla Rosa.

Desde sus primeros años mostró diferencias en relación con las personas de su edad "Su hermano Fernando la vio desde niña inclinada a cosas de Dios y vidas de santos, y tan honesta desde sus tiernos años, que jamás le vio más que la cara y las manos" (Ob. cit.:854).

En el solar de su casa hizo un jardín y levantó una ermita en donde pasaba en aislamiento y oración. 
Inicialmente usó hábito franciscano hasta que después tuvo contacto con los dominicos por su concurrencia a la iglesia de la Virgen del Rosario.

En 1606:

A los 20 años de edad, vistió el hábito de la Tercera Orden de la Penitencia de Santo Domingo. Como laica consagrada desde entonces, Rosa añadió a su apellido paterno el de "Santa María" y se comprometió a vivir a plenitud las normas de su institución, practicando las obras de misericordia en su hogar y desde su hogar, en los hospitales, rancherías, casas de vecindad y donde las necesidades del prójimo reclamaban sus servicios, cuidados y atenciones. (Álvarez Perca, 1997:218-20, t. I).

Queda claro que Rosa de Santa María no fue monja; ella fue "una laica cristiana comprometida con la causa de los que sufren" (Ibídem). "Murió a la edad de 31 años, el 24 de agosto de 1617, en su centro de trabajo, en casa de don Gonzalo de la Maza y de Doña María Uzátegui, donde Rosa trabajaba como maestra de sus hijas”. (Ob. cit.: 223).

Su entierro fue multitudinario. Congregó a todos los estratos de la sociedad limeña, encabezado por el virrey de ese entonces.

El 13 de febrero de 1668 el papa Clemente IX expidió la Bula de beatificación y su sucesor Clemente X dictó la Bula del 12 de abril de 167 1, elevándola a los altares como Santa Rosa Patrona de Lima, del Perú, América, Filipinas e Indias, mandando celebrar universalmente el 30 de agosto de cada año. (Álvarez Perca 1997:229-31, Vol. I). ${ }^{2}$

2 Salvador Velasco en El año Dominicano, consigna 1681 como año de la canonización; pág. 864. 


\subsubsection{Santa Rosa en las Tradiciones de Ricardo Palma}

Nuestro escritor dedicó tres tradiciones a la Santa. Responden a los títulos:

- Los mosquitos de Santa Rosa, que forma parte de la séptima serie publicada por la Imprenta del Universo, de Carlos Prince, Lima, 1889*

- El Rosal de Rosa, aparecida en la misma serie, año, ciudad e impresor*

- Los gobiernos del Perú, incluida en la quinta serie que vio la luz en Lima, Imprenta del Universo de Carlos Prince, en 1883."

Este estudio propone abordar cada texto por separado.

\subsubsection{Los mosquitos de Santa Rosa}

\section{Argumento}

Recoge una faceta de la vida de la santa que se presta para liberar la fantasía. Se trata de la convivencia armoniosa con los zancudos, con los cuales celebra un pacto tácito por el cual ella "no los molestaría"; y, ellos, como contrapartida, no la "picarían ni harían ruido".

El pacto implica una subordinación de los mosquitos a la santa, quien los induce a alabar a Dios por las mañanas y agradecer, al concluir el día, el bien de la vida recibido. En el intermedio, los mosquitos contaban con el permiso para que "vayan a buscar su alimento".

Palma, R. (2015) Tradiciones Peruanas. Edición, prólogo, notas, bibliografía e índices, Miguel Ángel Rodríguez Rea. Lima: Editorial Universitaria de la Universidad Ricardo Palma. 
La obediencia de los mosquitos como obligación profesada a Rosa de Lima va a ser confirmada con dos acontecimientos:

a) La agresión de los mosquitos a la beata Catalina como situación imprevista que da lugar a la muerte de uno de los que le habría picado en su visita no anunciada en la ermita. Este hecho activa la defensa de Santa Rosa, quien le dice: "Déjalos vivir, hermana; no me mates ninguno de estos pobrecitos, que te ofrezco no volverán a picarte, sino que tendrán contigo la misma paz y amistad que conmigo tienen”. (Palma, 1953:201).

b) Si en este primer caso la orden de la santa es para que no molesten a la beata Catalina, en esta segunda anécdota, dispone para que piquen a otra "beata de la Orden Tercera, que se resistía a acercarse a la ermita, por miedo de que picasen los jejenes" (Ibídem). La orden fue puntual y específica, cumplida por tres zancudos, obrando cada "uno en el nombre del Padre, otro en el nombre del Hijo y otro en el nombre del Espíritu Santo" (Ibídem).

\section{La estructura}

A esta tradición, por su contenido, se le reconocen tres partes:

a) La introducción, en la que presenta a los dos personajes:

1) Los zancudos, descritos a través de sus características: la picadura y el zumbido de su vuelo, altamente molestoso tanto a nivel individual o grupal; y

2) La Santa, a quien la refiere desde un plano de horizontalidad, para resaltar que la picada y bulla de los zancudos era un castigo más grave que sus propios cilicios, tormentos y 
mortificaciones, como una antesala para desarrollar la relación santa - mosquitos.

b) El cuerpo del texto. Le sirve al autor para exaltar su santidad a través de la capacidad de controlar la acción agresiva de los insectos, sobre la base del amor divino por la naturaleza, en tanto creación de Dios. Humaniza a estos insectos en cuanto los hace actuar como seres racionales capaces de adquirir un compromiso y cumplirlo.

c) La historia adicional con la cual Palma concluye la tradición, que busca reforzar los atributos de santidad de Rosa de Lima, insuflándole vida al gallito enfermo condenado a morir si es que no mejoraba.

\section{El humor}

Palma, fiel a su estilo, no hace de Santa Rosa un personaje seráfico, celestial, divinizado. La perfila en su dimensión humana, en el mundo terrenal, en una relación de igualdad con los mosquitos, unidos en la creación pero con cualidades sobrehumanas que las vive y ejerce con humildad, sin alarde, sin exagerar para establecer diferencias que la alejen de la persona común y corriente.

Las formas con las cuales se refiere a ella: "mi paisana Santa Rosa", "Rosa de Lima", "Rosa", "la santa", "nuestra santa" constituyen un indicador de la intención de cercanía entre la santa y el lector, con su figura sencilla, de vida cotidiana, pero que siempre sobresale aunque finamente perceptible.

Esta tradición no escapa al humor. Estando difuso en el contexto, en la tercera parte, con la historia del gallito, al que prácticamente resucita o evita su muerte; y, como seña de su vitalidad le hace cantar pícaramente. Palma configura de modo manifiesto el humor: 
iQuiquiriquí!

(iQue buen escape el que di!)

iQuiquiricuando!

(iYa voy, que me están peinando!) (Palma, 1953:201)

Nótese la modificación de la onomatopeya inicial del canto del gallo en la segunda vez, hecha con malicia, como recurso repentino, para servir de rima consonante con el último verso de remate y finalización de la narración.

Es, pues, la de Palma, una forma ingeniosa de ponerle cima a la seriedad del núcleo de la historia; y como los mosquitos no le brindaban una contextura para terminar haciendo reír, insertó la historia del gallo dentro del contexto de la familia, que sí le facilitaba el recurso para finalizar con humor.

Agréguese el análisis de la escritura del cuarteto compuesto. El primer verso está hecho de la onomatopeya del canto del gallo; pero el segundo, escrito entre paréntesis, expresa lo que quiere decir y lo que el que escucha y lee debe interpretar. En el tercero hay un híbrido logrado con parte de la onomatopeya y el adverbio "cuando", que nuevamente representa lo que quiere decir y lo que se debe interpretar, reforzado por los paréntesis y los signos de admiración entre los cuales es canalizado el sentido de los versos 2 y 4 .

\subsubsection{El Rosal de Rosa}

\section{El argumento}

Palma, esta vez, tiene a Santa Rosa como personaje central de la narración, Cuenta que ella habilitó un terreno libre de construcciones y sin uso de su casa, como "huerto y jardinillo". Allí brotó espontáneamente un rosal que sirvió para expandir 
esta planta en Lima "para embellecer corredores y las limeñas para adornar su rizas, negras y profusas cabelleras” (Palma, 1953:197)

Esta especie no existía en el Perú, pero al aparecer sin haber sido sembrada es un recurso literario para insinuar la santidad de la joven Isabel Flores; y, a la vez, convertir la rosa en el símbolo de su pureza de alma y predestinación de su santidad. También servirá para decidir su beatificación al realizar el milagro de hacer caer "perfumadas hojas de rosa... sobre la mesa" del Papa Clemente IX, quien se volvió devoto de la santa limeña a tal punto de beatificarla un 12 de febrero de 1669, proclamarla "Patrona de Lima y del Perú" y, "reformando la constitución de Urbano VIII...", simplificando "los trámites de canonización”.

Finalmente, la adhesión de Clemente IX a la beatificada Rosa de Lima se expresa "en un fuerte legado" que instituyó "en su testamento" "para construir en Pistoia, su ciudad natal, una espléndida capilla a Santa Rosa de Lima” (Palma, 1953:197).

\section{La estructura}

El rosal de Rosa consta de cuatro apartados:

a) El primero, se extiende entre el primer y segundo párrafo. Contiene la noticia del establecimiento del Hospital del Espíritu Santo, dedicado a marinos extranjeros cuyo edificio sirve de ubicación y referencia respecto al terreno de la vivienda y jardín de Isabel Flores Oliva, vecino a este.

Esta proximidad física de la casa de la futura santa lleva a confundir a Mendiburu sobre el origen limeño de las rosas, al imputarlo al hospital antes que al huerto de Flores Oliva. 
Implica el escenario físico, con localización en Lima donde acontecerán los hechos.

b) El segundo, que está dedicado a presentar, sin decirlo de manera expresa, la vida aislada, silenciosa, en confraternidad con la naturaleza, absorbida por el cultivo de las flores; expresión de belleza, delicadeza y del mundo ideal.

No hay palabra ni frase dedicada a su consagración a la oración, el martirio, la penitencia. Aborda la etapa juvenil, en el ambiente familiar de austeridad, sin mención a fiestas o reuniones sociales.

El núcleo se sitúa en el hecho de haber aparecido espontáneamente el rosal en el jardín de Isabel Flores.

Comienza ubicando el predio contiguo al hospital del Espíritu Santo. En esta propiedad los esposos FloresOliva fijarán su vivienda. En esta casa nacerá Isabel, hija de este matrimonio. Parte de este inmueble es habilitado por Isabel como huerto y jardín. Aquí transcurre esta etapa de su vida en el seno familiar.

Palma cierra este apartado informando del apogeo de las rosas, incluyendo su fama medicinal.

Comprende desde el tercer hasta el séptimo párrafos.

c) El tercer apartado se cuenta del octavo al décimo tercer párrafos. Da la información sobre los trámites de beatificación y menciona a los papas Clemente IX y X, así como al rey Felipe IV de España, quien usó su primera firma como monarca para solicitar la beatificación de Rosa de Lima. Termina el apartado con la noticia de las 
celebraciones de la beatificación, en cuyo día central los madrileños vieron en el firmamento "lucir una estrella vecina al sol".

Clemente IX, más allá de la vinculación legal por las resoluciones pontificias que expide, alcanza protagonismo al pasar de dudoso sobre la santidad de Rosa a convencido devoto de ella desde la "lluvia de rosas" hasta su legado para la edificación, a su costa, de una capilla en homenaje de la beata Rosa de Lima.

d) El cuarto apartado ha sido propuesto por Palma después de una separación con viñetas. Abarca los párrafos del decimocuarto al decimosexto, con el cual finiquita el texto.

En estos tres párrafos finales el narrador incorpora las noticias de las celebraciones limeñas de la canonización en 1672, indicando que hubo una inversión millonaria en platería para adornar calles, arcos, altares y joyas. También da cuenta que los propietarios en ese entonces de la casa y huerto familiar, "cedieron el terreno para que en él se edificase el Santuario de Santa Rosa de Lima”. Además, para no dejar cabo suelto a los advertidos lectores, Palma dice que "El rosal que ella cultivaba se trasplantó al jardín que tienen los padres dominicos, en el claustro principal de su convento" (Palma, 1953:198).

\section{La unidad textual}

Sirve el primer apartado, aparentemente ajeno, como hito referencial para la ubicación del escenario de la acción central que es la aparición espontánea y su cultivo del rosal por Isabel Flores Oliva en su vida familiar juvenil, en aislamiento y retiro del mundo terrenal. Complementariamente, con esta localización, 
aclara y refuta literariamente el error del historiador Mendiburu de señalar el origen limeño de la rosa, atribuyéndole al hospital de El Espíritu Santo contiguo a la casa de la santa.

Pasar del segundo al tercer apartado es acceder a la consecuencia lógica de una vida virtuosa, cuyo estilo extramundano desborda las fronteras virreinales, llega a la metrópoli y salta al Vaticano en solicitud de su reconocimiento espiritual que la encumbra a los altares. Concedido este, la vida de Rosa de Lima con su canonización se universaliza.

El cuarto apartado se liga al tercero porque recoge las manifestaciones sociales de júbilo por la canonización que se protagonizaron en Lima, tierra natal de la santa.

\section{El estilo}

La vida de la santa es resaltada a partir del hecho cotidiano y doméstico de cultivar flores y, de manera especial, rosas, sin participar de los deleites sociales.

Esta etapa juvenil de la vida en familia de la Santa está enmarcada en el tiempo y el espacio.

Respecto al elemento espacial, está ubicado en una zona no precisada de la Lima virreinal, en un solar contiguo al hospital El Espíritu Santo que se pinta como referente geográfico. En la vida post mortem, el escenario espiritual se traslada al Vaticano, por los trámites de beatificación y actuación del Papa Clemente IX. También en Pistoia, en donde se edificará una capilla; y a Madrid, en cuanto sede de las festividades de su beatificación.

El marco temporal transcurre desde 1581 en que el padre de la santa compra el terreno contiguo al hospital donde construye la vivienda familiar en la que nacerá la santa. Termina en 1672, 
con las festividades propias de su canonización, celebradas con toda pompa en Lima.

A estos dos componentes, Palma agrega una tercera delimitación de los hechos, trazando un marco político. Es el señalamiento de los gobernantes civiles y religiosos, en ejercicio al 30 de abril de 1586 día en el que gobernará como virrey interino el representante de la Real Audiencia de Lima, don Martín Enríquez, por muerte del titular. En el campo clerical, ejercerá el pontificado Sixto V y desempeñará el arzobispado de Lima, santo Toribio de Mogrovejo.

\section{Lenguaje y humor}

El nivel de lengua corresponde al coloquial, con incrustaciones de limeñismos y palabras creadas por él, resaltando el carácter criollo de la narración.

Es tan popular la visión y el tratamiento del tema, que verbaliza los hechos con soltura, fluidez, desenfado, donde por momentos impresiona su gracia como algo irrespetuoso y hasta irreverente.

Palma administra su seriedad sin llegar a lo incompresible. Siempre deja percibir una estela de humor colocada en el mundo del entorno de la santa, pero en ninguna parte del texto sobre la santa misma. A ella hace verla humana, pero no mundana. Distinta al común pero admirable y respetable. Terrenal, pero escogida para una vida sobrenatural y virtuosa.

El humor no exento de ironía lo ubica en el virrey interino

Aquel que después de veintiún meses de gobierno "se fue al mundo de donde no se vuelve sin haber hecho nada de memorable en el país". Y, como refuerzo de tal referencia irónica, suelta una valoración sarcástica al insistir: "Fue de los gobernantes que, a 
punto de obras públicas, realizan la de adoquinar la vía láctea y secar el océano con una esponja (Palma, 1953:197).

\subsubsection{Los gobiernos del Perú}

\section{El argumento}

Antes que humanas, política y moral, Palma pretende dar una explicación religiosa a los malos gobiernos que durante la república ha tenido el Perú. Para ello construye literariamente un diálogo, simple y breve, entre santa Rosa de Lima, la santa peruana, con Dios, ante quien formula algunas peticiones para el bien de su patria. La primera versa sobre un clima benigno; la segunda sobre recursos y riquezas naturales; ambas concedidas de buen talante. Ante la tercera, referida a la virtud de las mujeres e inteligencia de los hombres, Cristo, "el Rey del cielo y tierra", cambia de humor y va a conceder la petición no con mucho agrado. Dios, más dispuesto a terminar el diálogo que a seguir escuchándola, al despedirse recibe el cuarto y último ruego:

—Sí, Señor. Dale a mi patria buen gobierno.

Aquí, amoscado el buen Dios, le volvió la espalda, diciendo:

— iRosita! iRosita! ¿Quieres irte a freír buñuelos? (Palma, 1953:233)

Con este texto, el lector deduce que el pedido de santa Rosa, al no tener pronunciamiento expreso, por el gesto de darle la espalda y la pregunta por respuesta, el pedido fue denegado.

Pero, con el ánimo de ponerle fin a la duda si aceptó o no, con el ademán y la interrogante de respuesta, Palma afirma que otra fuera la suerte del Perú si es que "la santa hubiera comenzado a pedir por donde concluyó”. (Ibídem) 


\section{La estructura}

Es un texto corto de crítica política expresada con humor e ironía contra los gobiernos del Perú republicano que no construyeron patria por uso inmoral del poder; pero al no encontrar una razón humana que explique el desastre, recurre a la fantasía literaria para encontrar una causa en la ingenuidad de la santa que no le permite manejar el sentido de priorización y de oportunidad para formular sus pedidos.

No es reproche ni imprecación a la santa. Más bien ajena a las intrigas políticas, le faltó malicia para pedir ese don.

El texto tiene un desarrollo muy ágil, argumento concentrado que no dispersa la atención del lector y le permite captar un mensaje de crítica de moral política contra los gobiernos, revestido de una aparente causa de religiosidad.

Consta de las tres partes clásicas del discurso:

a) Introducción, contenida en el primer párrafo que advierte seguir un modelo de diálogo entre Santa Teresa y Cristo, advirtiendo que no es copia, sino una tradición, que opta por contarla dejando a criterio del lector su originalidad.

b) Cuerpo del discurso, que comienza diciendo: "Un día en que estaba el buen Dios dispuesto a prodigar mercedes, tuvo con Él un coloquio Santa Rosa de Lima”. Termina con la expresión de incomodidad de Cristo por el pedido, lanzada al aire: "iRosita! iRosita! ¿Quieres irte a freír buñuelos?", que es una forma familiar y afectiva de comunicar que no tiene nada que contestarle; y

c) La conclusión, opinión directa y concreta de Palma que en esta narración hace de tercero observador y testigo. 
Los personajes son Dios y santa Rosa, pero humanizados, absorbidos por asuntos mundanos: el clima, los recursos naturales, el temperamento de las personas; el desempeño de los gobiernos.

Dios está tan humanizado que maneja su humor entre la complacencia y el fastidio, con bondad limitada y enigmas sin explicaciones. Prefiere el tono de desagrado y la frase evasiva, antes que la negación dura, expresa y directa.

Palma, el autor, es un tercero observador oculto que al final oficia de testigo y fedatario tácito, cuyo papel le permite contar la historia y emitir su juicio crítico como conclusión.

\subsection{San Martín de Porres}

Palma presentó la santidad de Martín de Porres en dos tradiciones, cuyos títulos son:

- Los ratones de fray Martín, que llega a los lectores conformando la octava serie publicada en Lima, en 1891, por la Imprenta y Librería El Universo de Carlos Prince; y,

- El por qué fray Martín de Porres, santo limeño, no hace ya $\underline{\text { milagros, }}$ publicada dentro de la novena serie, a cargo de la Imprenta Torres Aguirre, Lima, 1899."

\subsubsection{Una biografía sumaria}

Martín fue bautizado el 9 de diciembre de 1579 en la parroquia de San Sebastián, en cuya acta el párroco solo coloca el nombre y condición social de la madre Ana Velásquez y de los padrinos, refiriéndose a la filiación paterna como "hijo de padre no conocido" (Rodríguez Crespo, 1964:62). 
Posteriormente se descubre por él mismo la identidad del padre, quien es don Juan Porras o Porres "caballero español de noble alcurnia, natural de Burgos, cruzado de la orden militar de Alcántara... La madre era una joven morena libre nacida en Panamá hacia 1560 y que acompañó al Perú al caballero burgalés" (Ob. cit.:62-63). Este origen significa que Martín tendrá la condición social de mulato que, junto al zambo "fueron siempre resultado de una unión no aceptada por la sociedad ni por las leyes" (Ob. cit.:62).

Martín y su hermana menor Juana no disfrutaron de un ambiente familiar regular juntos, de modo permanente con sus progenitores. Su padre los visitaba. Ellos vivían en un barrio pobre de Lima.

Un día su padre recogió a sus dos hijos y los llevó a Guayaquil. A pocos años regresó con Martín a Lima, entregándosela nuevamente a su madre.

Por los 11 años, siguiendo a Rodríguez Crespo, Martín se inició en la barbería en la botica de Mateo Pastor. En esos tiempos, en estos establecimientos se atendían "sangrías y se trataban males como heridas, úlceras y apostemas" (Ob. cit.:65). Sobre este pasaje de la vida de Martín, Gago de Val en la biografía inserta en Martinez Puche, El año Dominicano (2016), afirma que "A los once años es escogido por el doctor Marcelo de Rivero, barbero y cirujano, como "chico para todo", que pronto ascenderá al grado de aprendiz por sus dotes y buena disposición" (Ob. cit.: 1177).

Por su parte, fray Guillermo Álvarez Perca manifiesta que Martín, hasta antes de ingresar al convento, "había frecuentado

* Palma, R. (2015) Tradiciones Peruanas. Edición, prólogo, notas, bibliografía e índices, Miguel Ángel Rodríguez Rea. Lima: Editorial Universitaria de la Universidad Ricardo Palma. 
el consultorio del Dr. Marcelo de Rivero y la farmacia de Don Mateo Pastor, con el propósito de aprender el arte de curar y preparar medicamentos, para socorrer a los enfermos y pobres" (1997:233, Vol. I).

Integrando ambos datos históricos y completando el perfil humano ya teñido de santidad precoz, agrega que Martín después de su jornada, “iba 'derechito' a las rancherías y galpones a continuar su obra de caridad con los esclavos, indios y pobres enfermos" (Ibídem).

Volviendo a Gago de Val, da la noticia de que el segundo arzobispo de Lima Santo Toribio de Mogrovejo también confirmó a Martín cuando contaba los doce años de edad (Ob. cit.:1 177).

En 1595, de acuerdo a la data de Gago de Val, cuando Martín tenía dieciséis años de edad, ingresó al convento de Santo Domingo en calidad de donado. Como tal se ocupaba de barrer el convento y la iglesia. Posteriormente, en forma excepcional, en 1603 los dominicos lo aceptan "como Hermano con los votos de pobreza, obediencia y castidad" (Rodríguez Crespo; Ob. cit.:70).

Convertido en enfermero protagoniza curaciones prodigiosas. Atiende de modo infatigable, traspasando paredes y puertas cerradas; curando a la vez a varios enfermos.

También practica la caridad, la humildad. Recoge enfermos abandonados. Cuando se le prohíbe internarlos en su celda o en el convento, habilita la casa de su hermana Juana como un pequeño hospital.

Después de 45 años en el convento y con 60 años de edad, fray Martín de Porres entregó su alma a Dios el 3 de noviembre de 1639. 
En la cronología de Gago de Val, el papa Gregorio XVI beatificó a Martín el 8 de agosto de 1837 y San Juan XXIII lo santificó el 6 de mayo de 1962. (Ob. cit.:1184).

\subsubsection{Los ratones de fray Martín}

\section{El argumento}

De tantos milagros realizados por el hermano lego, Fray Martín de Porres, ya enfermero en el convento de Santo Domingo en Lima, Palma elige la historia de los ratones, y, particularmente, aquella en que fue invitado a comer en "sana paz", en el mismo plato, con el perro y el gato, en esos tiempos enemigos reconocidos.

Para llegar a este episodio informa de la aparición de una plaga de ratones en el monasterio, dentro del cual invadían "celdas, cocina y refectorio". Narra que los sacerdotes comenzaron a poner trampas con poco éxito, incluso el propio Martín hizo algo parecido en la enfermería; trampa en la cual cayó un pericotito al que liberó cariñosamente, pidiéndole que él y sus compañeros fueran a vivir a la huerta; lugar en el que él les proveería diariamente comida.

Comenta Palma que "El embajador cumplió con la embajada, y desde ese momento, la ratonil muchitanga abandonó el claustro y se trasladó a la huerta". A la vez cuenta que "los pericotes acudían como llamados con campanilla" cada mañana que Fray Martín les llevaba la comida (Palma, 1953:265).

Antes de este milagro capital en la valoración del narrador, fray Martín ya tenía a perro y gato compartiendo los alimentos. El ratoncito fue el tercer invitado para configurar lo imposible, de no mediar la santidad temprana de Martín. 
Detalla Palma que "Mirábalos una tarde comer en sana paz, cuando, de pronto, el perro gruñó y encrespose el gato". Restaurando el ambiente de armonía perrogatuna, Martín invitó al ratoncito pidiéndole a los otros: "—Vaya, hijos, denle siempre un lugarcito al convidado, que Dios da para los tres". Desde esa fecha, el pericotito, "comió en amor y compaña con perro y gato" (Ibídem).

\section{Estructura del texto}

Es fácilmente identificable las tres partes clásicas del discurso:

a) La introducción, un poco larga en la que da cuenta de la fuente de su información. Principalmente está destinada a presentar al personaje central, proporcionando sus datos biográficos básicos y enumerando un par de milagros como muestra selecta de su fecundidad que Palma pondera comparando: "hacía milagros con la facilidad con que otros hacen versos". Puntualiza dos, que los expone como impactantes: Uno, relativo a la caída de un albañil al que lo detiene en el aire hasta obtener la licencia de su superior. El otro, visto a la luz de la lógica resulta ingenuo, pues Martín lava el pan de azúcar negra en la pila del convento, al que saca del agua, "blanco y seco". Ve el hecho tan poco admisible por la razón que, como autor, dirigiéndose a sus lectores, exclama: "Ea, no me hagan reír, que tengo partido un labio” (Palma, 1953:264).

b) El cuerpo del discurso, enfilado a la historia de los ratones, la obediencia de estos al lego dominico y la audacia de uno de ellos en aparecer en la celda de Martín cuando comían en el mismo plato el perro y su gato, siendo incorporado para compartir sin agresiones ni rivalidades. 
c) La conclusión, sumamente breve, que representa la apreciación personal del autor que obra como tercero ajeno a la historia, pero en papel de testigo oculto que da fe del hecho, diciendo: "Y el ratón, sin hacerse rogar, aceptó el convite, y desde ese día comió en amor y compaña con perro y gato" (Palma, 1953:265).

\section{Los personajes}

El hermano Martín es el personaje principal y activo, autor de todos los milagros relatados como fruto de su santidad tempranamente manifiesta.

En el plano humano y en papeles secundarios, están el prior y el albañil. El primero como regulador de la acción cristiana y milagrosa de Martín, alegando un orden disciplinario propio del convento. El segundo, el albañil, beneficiario del milagro, actuante en la escena única de su caída del andamio.

En el plano zoológico, actúan los ratones en dimensión colectiva e individual, sometidos a través del amor a obediencia al santo, y capaces de acordar la obligación de vivir en el huerto en cuyo lugar recibirían su comida.

El ratoncito incorporado es el del papel heroico, que despierta ternura y simpatía.

Completan el cuadro animalesco, el gato y el perro, convivientes en paz por gracia del amor del santo dominico.

Actúan como en las fábulas, animados y humanizados. 


\subsubsection{El por qué fray Martín de Porres, santo limeño, no hace ya milagros}

\section{El argumento}

Desde el título de la tradición, Palma sugiere el contenido del texto. Asumiendo literariamente la defensa del santo, explica al lector que fray Martín ya no hacía milagros no porque se hubiera agotado su santidad sino por la prohibición expresa del prior del convento, impartida bajo compromiso de obediencia santa.

Ocurrió en vida del hermano dominico, ante tanta concurrencia a la enfermería en solicitud de milagros. Después de su muerte, esta prohibición se renovó por el prior ante la tumba del beato, cesando, en definitiva, la realización de nuevas gracias.

En vida, la prohibición se atenuaba con la licencia previa, como el narrador que ilustra con el caso del albañil que caía del andamio y que quedó suspendido en el aire, hasta su regreso, una vez obtenido el permiso.

Cabe indicar que este caso también aparece en la cuenta de los milagros en la otra tradición escrita en homenaje a San Martín de Porres: Los ratones de fray Martín, aunque con menores detalles.

Palma enfatiza la renovación de la prohibición, con el siguiente párrafo:

- Hermano Martín, cuando vivías en el mundo obedeciste humildemente mis mandatos, y no he de creer que en el cielo te hayas vuelto orgulloso y rebelde a tu superior jerárquico, negándole la santa obediencia que juraste un día. Basta de milagros. Te intimo y mando que no vuelvas a hacerlos (Palma, 1953:367). 


\section{La estructura del texto}

Responde a las tres consabidas secciones:

a) Introducción. Desde el primer renglón y en primera persona gramatical, Palma destaca en el santo la cualidad de fecundo productor de milagros. Luego discurre con inserciones de hechos como su pobreza, los tiempos en que vivía el santo, la anécdota del tirano argentino Juan Manuel Rozas y su amanuense con la técnica narrativa de referirse al propio Palma como el autor del texto, optando por aceptar el contenido del panegírico y no discutir para evitar las dificultades que le podría acarrear.

b) El cuerpo del discurso. Se inicia con el párrafo "Fuera el cigarrillo. Vuelvo a mis carneros, esto es a los milagros..." (Palma, 1953:366). En relación con estos, Palma, anuncia la congestión de gente que asiste a la portería del convento en busca de fray Martín para solicitarle milagros. Incluso consigna uno baladí referido a una dama de rostro muy feo que pretendía ser embellecida por Martín.

La constante congestión de personas promueve en el prior la necesidad de prohibirle a Martín "bajo de santa obediencia... que haga milagros sin pedir(le) antes permiso" (Ibídem).

Limitado ya el hermano Martín en su espontaneidad milagrera, acontece la caída del albañil que queda en suspenso hasta el regreso del lego premunido de la autorización del superior a la que estaba obligado.

Ocurrido el fallecimiento del beato, los milagros continuaban produciéndose, tan igual como las visitas de los creyentes a la tumba del santo. 
Es a consecuencia de ello que nuevamente el prior va a la tumba y vuelve a prohibirle al santo la realización de sus numerosos milagros; $\mathrm{y}$

c) La conclusión. Está expresada en dos pequeños párrafos, ahora con frases de la apreciación del propio autor:

Y que nuestro santo paisano acató y sigue acatando la imposición de su prelado lo comprueba el que, ni por bufonada, se ha hablado de milagros prodigiosos por él realizados después del año 1640 (Palma, 1953:367).

\section{El estilo y la ironía}

Con un nivel de lenguaje conversacional, ágil, fluido y gracioso, empleando alternativamente la primera y tercera persona gramatical, Palma, conserva la presentación humana del bienaventurado con una actitud de inocencia, alma limpia y un corazón muy generoso, dentro de una dimensión terrenal de cercanía con el lector. Lo trata de "mi paisano" o "milagrero", pudiendo dar la impresión de afectar el respeto. Pero no. La atmósfera que crea Palma es de humor, que se nota en forma más clara en pasajes como estos:

De mis cocos, pocos. Bástele al lector saber que como el viejo Porres no le dejó a su retoño otra herencia que los siete días de la semana y una uña en cada dedo para rascarse las pulgas, tuvo este que optar por meterse lego dominico y hacer milagros (Palma, 1953:365).

También, cuando cuenta Palma que concurrió en demanda de embellecimiento “... la Carita de Cielo, hembra que como fea no tenía nada que pedirle a Dios...”; “... milagro que dizque no pudo, no quiso o no supo hacer fray Martín” (Palma, 1953:366). 
Resulta igualmente risible que "el verdugo de Málaga, que se murió de pena porque a un conocido suyo le echó el sastre a perder unos pantalones sacándoseles estrechos de pretina" (Palma, 1953:367).

Finalmente, con el párrafo de remate del texto que desenfadadamente dice: "Lo que es ahora, en el siglo XX, más hacedero me parece criar moscas con biberón que hacer milagros" (Ibídem).

\section{La apreciación literaria de conjunto}

\subsection{Ricardo Palma, el autor}

Es el escritor peruano de la primera generación republicana. Nace en Lima en 1833, una década después de la declaración de la independencia por José de San Martín y de la batalla de Ayacucho.

Su obra insurge dentro del movimiento romántico y se desarrolla en paralelo con el radicalismo de Manuel González Prada.

Palma es libertario y anticlerical. Cultiva y publica poesía desde 1855, su primer libro, y seguirá escribiendo y publicando en décadas posteriores hasta Verbos y gerundios, en 1877 (Tauro del Pino; 2001:1923, t.12).

Respecto a las tradiciones, la cronología de Díaz Falconí registra un total de 559, escritas entre 1851 a 1917, que fueran publicadas en forma suelta en periódicos y revistas de la época y conformando series desde 1872 hasta 1910, bajo el título de Apéndice a mis últimas tradiciones peruanas. (2015:30).

Teniendo en cuenta la data, Los gobiernos del Perú y Los mosquitos de Santa Rosa, son de 1890; El rosal de Rosa, viene de 1886. 
Las relativas a San Martín de Porres, la tradición Los ratones de fray Martín de Porres data de 1890, y El por qué fray Martín de Porres el santo limeño no hace ya milagros viene de 1906. (Ob. cit.:195-196-200-205).

Palma ejerce el periodismo en forma activa. Fundador de la Academia Peruana de la Lengua. Director de la Biblioteca Nacional después de la guerra con Chile. Escribió ensayos históricos y de crítica literaria. Organizó diccionarios de peruanismos y americanismos bajo los títulos de Papeletas Lexicográficas y Neologismos y Americanismos.

Leyó la colección de clásicos castellanos e incursionó en la política como Secretario del Presidente José Balta y Senador por Loreto.

Su estilo influyó en escritores del Perú y de los países de habla hispana.

Falleció en Lima, en 1919.

\subsection{La obra que lo inmortaliza}

Unánimemente, la crítica literaria peruana y extranjera, en su tiempo y actualmente, califica a la tradición como un logro de literatura clásica.

Estuardo Núñez en Ricardo Palma, escritor Continental escribe: "Así, Palma dio nacimiento a un nuevo género literario, a una nueva forma de concebir el pequeño mundo que le rodea, a una expresión de estilo distinto y personal en el grato oficio de escribir sus narraciones". (1998:XI). 
Alessandro Martinengo en su libro El estilo de Ricardo Palma (2007) se pregunta ¿qué es la tradición? Y él mismo da la respuesta configurándola como "una narración breve, a veces muy breve, construida alrededor de un fundamento histórico y rica de todos los matices del humor y la fantasía. Una delicada mezcla, pues, de historia e invención..." (Ob. cit.:72).

Esta noción sobre la tradición, como la totalidad de variantes, aun comprendiendo la del propio Palma, considera el humor como elemento compositivo infaltable. Un estudioso del humor, Roy L. Tanner sostiene que toda la obra de Palma está infiltrada de este. Y no solo usa el humor sino que "Critica, ironiza, satiriza o trivializa según lo demande la ocasión o su "musa cómica", pero siempre con una conciencia estricta del molde estilístico en el que desea moldear su humor". (2005:19).

Las tradiciones dedicadas a santa Rosa y a san Martín de Porres, calzan en el molde del género literario creado por Palma. Cada una es una narración breve en la que el personaje está retratado a través de sus acciones. No describe los espacios e intensifica la ocurrencia de los sucesos para darle fluidez. Todo ello expresado en un lenguaje coloquial que discurre en diálogos, incluyendo modismos, refranes, versos y técnicas de cambios inesperados que, en conjunto, logra un texto ameno que interesa al lector.

Tanner señala que la ironía está en la obra y el autor. En las tradiciones estudiadas respecto al tratamiento de los personajes centrales que son santa Rosa y san Martín de Porres, los presenta en su dimensión humana, en menesteres cotidianos, cuyas acciones no les da el cariz de milagros. Sí, ha escogido elementos propios para fabular, para liberar su fantasía y a través de ella construir la crítica, la ironía, dotando al texto de una atmósfera agradable y con fino humor. 
Desde otro ángulo de valoración, santa Rosa de Lima y san Martín de Porres fueron en su tiempo y son hasta ahora populares. No solo están en los altares de los templos sino habitan en la fe y en la creencia de los pueblos. Esta presencia social y sus singularidades individuales propias de una santidad forjada dentro del pueblo, constituyeron fuerzas impulsoras de la incorporación en la literatura, como es el caso de las tradiciones de Palma.

Rodríguez Crespo en su obra varias veces citada, concluye las biografías de ambos santos afirmando:

El elemento criollo encontró en Santa Rosa su más noble expresión y la mezcla de razas nos dio a Martín, productos ambos de la tierra y de la sangre peruana; por eso sus figuras se explican mejor en la sociedad del siglo XVII, porque su santidad refleja el ambiente en el que van a cumplir su misión. Pero si bien como hemos visto, constituyen inspiración moral de su época, trascienden a los límites del tiempo y las fronteras. (1964:93).

Santa Rosa de Lima y san Martín de Porres, por sus caracterizaciones, reúnen todos los requisitos para protagonizar personajes literarios, en una expresión del arte verbal que, por asociación de contraste con la literatura religiosa, se los considera en este ensayo como personajes de una literatura laica; es decir, sin intención de mensajes de fe y espirituales. Su mensaje es estético, social, cultural y político. 


\section{Bibliografía}

Álvarez Perca, G. (1997-1999). Historia de la orden dominicana en el Perú, siglos xvi a xx. 3 vol. Lima

Díaz Falconí, J. (2015). “Cronología de las tradiciones peruanas” en Tradiciones peruanas, de Ricardo Palma. Lima: Universidad Ricardo Palma, vol. VIII.

Díez De Velasco, F.(2014). Breve historia de las Religiones. España: Alianza Editorial, segunda edición.

Hampe Martínez, T. (1998). "Descubrimiento, conquista y virreinato, siglo XVI" en Compendio Histórico del Perú. España: Editorial Milla Batres, t. II, segunda edición.

Martinengo, A. (2007). El estilo de Ricardo Palma. Lima: Universidad Ricardo Palma.

Martínez Puche, J. A. (2016). El año Dominicano. España: Colección Bolonia, Serie Maior, EDIBESA.

Nieto Vélez, A. (1981). "La Iglesia Católica en el Perú”, en Historia del Perú, Procesos e Instituciones. España: Editorial Juan Mejía Baca, t. XI.

Núñez, E. (1998). Ricardo Palma, escritor continental, Lima, Banco Central de Reserva del Perú.

Palma, R. (2015). Tradiciones peruanas. Lima, Universidad Ricardo Palma, 8 vols.

Palma, R. (1953). Tradiciones peruanas completas. Madrid, Aguilar Ediciones, segunda edición.

Rodríguez Crespo, P. (1964). Santa Rosa de Lima-San Martín de Porres, Lima, Biblioteca Hombres del Perú. 
Tanner, R. L. (2005). El humor de la ironía y la sátira en las tradiciones peruanas. Lima, Universidad Ricardo Palma.

Tauro Del Pino, A. (2001). Enciclopedia ilustrada del Perú. Lima, 17 tomos.

Recibido el 1 de marzo del 2018

Aceptado el 16 de marzo del 2018 